\title{
ESFERAS PÚBLICAS TRANSNACIONAIS: ENTRE O REALISMO VESTFALIANO E O COSMOPOLITISMO *
}

\section{RESUMO}

EM RESPOSTA À CRISE DE VESTFÁLIA, PROPOSTAS DE DEMOCRACIA COSMOPOLITA FICAM COMPROMETIDAS DIANTE DA ASSIMETRIA DE PODER QUE MARCA AS RELAÇÕES INTERNACIONAIS E PELAS DIFICULDADES EMPÍRICAS DE CONSTITUIÇÃO DE UM ARRANJO INSTITUCIONAL CAPAZ DE CONFERIR LEGITIMIDADE NORMATIVA E EFICÁCIA POLÍTICA ÀS DECISÕES TOMADAS EM ESFERA PÚBLICA: QUEM DEVE PARTICIPAR DAS DELIBERAÇÕES E QUEM É O DESTINATÁRIO DAS COMUNICAÇÕES GERADAS NA SOCIEDADE CIVIL MUNDIAL? No ENTANTO, AFIRMO QUE SE CONSOLIDARAM ESFERAS PÚBLICAS TRANSNACIONAIS QUE ABREM NOVAS POSSIBILIDADES DE TEMATIZAÇÃO E SOLUÇĀO DE PROBLEMAS NACIONAIS ANTES EXCLUSIVAMENTE TRATAdOS NO ÂMBITO dO ESTADO-NAÇÃO. NESTE ARTIGO, PRETENDO EXPLORAR AS POSSIBILIDADES DE AMPLIAÇÃO DA INFLUÊNCIA E PODER DOS ATORES DA SOCIEDADE CIVIL SOBRE O ESTADO NACIONAL A PARTIR DO RECURSO A ESSAS ESFERAS PÚBLICAS TRANSNACIONAIS.

\section{PALAVRAS-CHAVE}

COSMOPOLITISMO; RELACÕES INTERNACIONAIS; ESFERAS PÚBLICAS transnacionais; Democracia; Direitos humanos; Redes TRANSNACIONAIS.

\author{
Márcia Nina Bernardes \\ TRANSNATIONAL PUBLIC SPHERES: \\ BETWEEN WESTPHALIAN REALISM AND COSMOPOLITANISM
}

\begin{abstract}
COSMOPOLITAN DEMOCRACY PROJECTS, WIDELY DISSEMINATED VIS-A-VIS THE WESTPHALIAN CRISIS, ARE COMPROMISED TO THE EXTENT THAT DO NOT ADEQUATELY TAKE INTO CONSIDERATION THE POWER ASYMMETRIES IN INTERNATIONAL RELATIONS AND THE EMPIRICAL DIFFICULTIES IN BUILDING AN INSTITUTIONAL APPARATUS CAPABLE OF GRANTING NORMATIVE LEGITIMACY AS WELL AS POLITICAL EFFICACY TO DECISIONS TAKEN IN THE PUBLIC SPHERE: WHO SHOULD PARTICIPATE IN THE DELIBERATIONS AND WHO IS THE RECIPIENT OF THE COMMUNICATIONS ORIGINATED IN THE SO-CALLED GLOBAL CIVIL SOCIETY? NEVERTHELESS, I CONTEND THAT THERE ARE TRANSNATIONAL PUBLIC SPHERES WHICH PROVIDE NEW POSSIBILITIES OF THEMATIZATION AND SOLUTION OF PROBLEMS WHICH HAD BEEN DEALT BEFORE EXCLUSIVELY WITHIN THE NATIONAL STATE FRAMEWORK. THIS ARTICLE AIMS AT EXPLORING THE POTENTIALS FOR INCREASING CIVIL SOCIETY ORGANIZATION'S INFLUENCE AND POWER OVER THE STATE, THROUGH THE RESORT TO TRANSNATIONAL PUBLIC SPHERES.
\end{abstract}

\section{KEYWORDS}

GLOBALIZATION; COSMOPOLITANISM; INTERNATIONAL RELATIONS; TRANSNATIONAL PUBLIC SPHERES; HUMAN RIGHTS;

TRANSNATIONAL NETWORKS.

\section{INTRODUÇÃO}

A globalização parece ter destruído a ordem mundial, sem ter inaugurado uma nova. Zigmunt Bauman observa que a noção de globalização substituiu gradativamente a de "universalização", que foi indispensável para a autocompreensão moderna e, hoje, é encontrada apenas em discursos filosóficos e, às vezes, em discursos jurídicos. A ideia 
de universalização aludia à intenção de produzir ordem e significado em uma escala global e estava associada a conceitos como "civilização", "desenvolvimento" e "consenso”. O termo globalização, no entanto, não reteve nenhum desses significados. Ele não denota projetos intencionais, mas sim efeitos globais de processos supostamente incontroláveis e imprevisíveis. Estados parecem estar se adaptando a imperativos do mercado global que não podem controlar, em vez de forjar suas próprias políticas econômicas. Tornar-se globalizado não é algo que possamos ou queiramos fazer, mas é algo que está acontecendo com todos nós. Segundo Bauman (1999, p. 68-69), o significado mais profundo da globalização é de indeterminação, dispersão, falta de controle e automação de processos globais, gerando a sensação de estar à deriva.

Diante deste cenário de indeterminação, emergem diferentes visões sobre a ordem pós-vestfaliana. ${ }^{1}$ Céticos realistas afirmam que estamos diante de um novo capítulo do capitalismo e que questões de poder, que só podem ser articuladas a partir de uma racionalidade instrumental, continuam determinantes. Nesta visão, falar de uma democracia global, ou de um constitucionalismo global, é, na melhor hipótese, um esforço ingênuo, e, na pior, uma tentativa de camuflar projetos imperialistas hegemônicos. Em uma perspectiva oposta, anunciam-se propostas de democracia cosmopolita, animadas pelo vislumbre de uma sociedade civil global, emergente e ainda ocasional, que permitiria a aposta na realização do ideal normativo da democracia em escala global.

Inspirada pelas premissas metodológicas da teoria do discurso de Jürgen Habermas, sustento neste artigo que a validade das propostas cosmopolitas fica comprometida pela facticidade da enorme assimetria de poder que marca as relações internacionais e pelas dificuldades empíricas de constituição do aparato institucional capaz de cumprir as funções assinaladas pela teoria discursiva da democracia deliberativa ao Estado Nacional: quem é o destinatário das comunicações geradas na sociedade civil mundial? Nancy Fraser (2009, p. 48-75) refere-se a essas dificuldades como problemas de "enquadramento" em tempos de um discurso "abnormal" de justiça. Nesse contexto anormal, coloca-se em xeque o próprio desenho institucional pressuposto na formulação de reivindicações de justiça e que me permitira discernir "quem" pode reivindicar "o que” de forma legítima.

Mas, ainda que no cenário atual haja problemas conceituais e políticos nas teorias cosmopolitas (COSTA, 2005), os processos que vêm forjando essa sociedade civil transnacional criaram esferas públicas transnacionais que abrem novas possibilidades de tematização e solução de problemas antes exclusivamente tratados no âmbito do Estado-nação. Neste artigo, pretendo explorar as possibilidades de ampliação de influência e poder dos atores da sociedade civil sobre o Estado nacional a partir do recurso a essas esferas públicas transnacionais.

Este trabalho não se destina, pois, a tratar das preocupações mais comuns na literatura sobre a esfera pública no tocante à governança global, como, por exemplo, 
os déficits da democracia atual causados pela globalização e a necessidade de novos conceitos de soberania e constitucionalismo. Com efeito, o presente artigo é uma tentativa de interpretar novas configurações transnacionais à luz das agendas políticas domésticas, e não de tratar das implicações normativas de tais novos arranjos para o direito e políticas internacionais. ${ }^{2}$ Para usar uma distinção habermasiana, não se toma aqui a perspectiva dos cidadãos cosmopolitas, que é orientada por padrões universalistas, mas sim a perspectiva dos cidadãos nacionais, que se transnacionalizam para reivindicar seus direitos (HABERMAS, 2008, p. 447).

Na próxima seção, tratarei do conceito de esfera pública tal como pensado originariamente na teoria do discurso. Pretendo aqui ressaltar as premissas nacionais do modelo de circulação de poder pressuposto nessa teoria e apontar os momentos em que podem haver obstáculos às lutas por emancipação. Na Seção 2, problematizo essas premissas institucionais a partir da crise do direito e das relações internacionais vestfalianos. Na Seção 3, apresento mudanças ocorridas no direito internacional que possibilitaram um regime internacional de direitos humanos e geraram organizações internacionais com características e funções diferentes daquelas típicas de Vestfália, fornecendo bases institucionais para as esferas públicas transnacionais. Na Seção 4, discuto o surgimento de uma sociedade civil transnacional e o funcionamento de esferas públicas transnacionais.

\section{Sobre o CONCEITo discursivo DE ESFERA PÚblicA}

A versão da democracia deliberativa afirmada pela ética do discurso de Jürgen Habermas tem a pretensão de manter as aspirações normativas de validade inerentes ao conceito de democracia, expressas pelas noções de soberania popular e direitos humanos, ao mesmo tempo em que leva em consideração a facticidade contemporânea e os limites impostos pela complexidade administrativa própria de sociedades de massa. Para Nancy Fraser, é vital que a opinião pública discursivamente gerada tenha eficácia política, além da legitimidade normativa, para que se mantenha seu potencial crítico (FRASER, 2009, p. 76-77). Posições altamente idealizadas perdem sua força como referencial crítico para análise de políticas e instituições existentes.

Com efeito, a tensão entre o que Habermas chama de "faticidade" e "validade" não corresponde à oposição entre realidade e norma. A teoria discursiva olha para o conteúdo normativo da democracia em práticas políticas cotidianas. Tal método pressupõe uma análise sociológica e uma reconstrução normativa. Neste espírito de "crítica imanente", requer-se "que normas que informam a crítica social sejam de algum modo observadas, ainda que de forma distorcida, nas práticas sociais e econômicas existentes" (POWER, 1998, p. 207). ${ }^{3}$

Nesse sentido, as possibilidades de exercício da soberania popular em condições contemporâneas pressupõem a distinção conceitual entre "sistema político", entendido 
como aparato burocrático do Estado, e "esfera pública”, entendida como um espaço social e comunicacional que permite as trocas entre o sistema e domínio privado, ou mundo da vida no jargão habermasiano. ${ }^{4}$ Em sociedades plurais de massa, onde a interação face a face no modelo da polis grega não é mais possível, o lugar por excelência para a deliberação política e autodeterminação democrática migra do sistema político para as esferas públicas. Apenas nesses loci não estatais de deliberação são possíveis a formação coletiva da vontade, a justificação de decisões previamente acertadas e o forjamento de novas identidades. Soberania popular é reinterpretada intersubjetivamente e exercida na esfera pública por meio de processos comunicativos de formação coletiva da vontade. Assim como em Rousseau a noção de soberania foi deslocada do Estado, detentor do monopólio da coerção, para o povo (ou para a vontade geral), em Habermas (1997, p. 23), ela é "absorvida pelas formas de comunicação destituídas de sujeito" e passa a ser atributo não de sujeitos individuais ou coletivos, mas dos procedimentos democráticos e das suas pressuposições comunicativas.

Neste modelo, o direito e a proteção dos direitos humanos são a garantia de acesso equitativo à esfera pública, o primeiro funcionando como um mediador da integração social entre estranhos. Ao mesmo tempo, de acordo com esta perspectiva, o direito é também o resultado de um processo deliberativo, no qual todos afetados pelas consequências de uma norma podem participar da sua criação, preservando a soberania popular.

A institucionalização da dinâmica de formação discursiva da vontade política se dá por meio de um modelo de circulação de poder que pressupõe uma divisão de tarefas entre o sistema político e as esferas públicas. De fato, a capacidade de as esferas públicas fornecerem respostas e de lidarem com os problemas que identificam é limitada. O sistema político é mais bem equipado para implementar soluções viáveis. Segundo esse modelo, o poder político circula entre o domínio privado da vida social (ou “mundo da vida”, para Habermas) e o sistema político, passando pela esfera pública.

Essa circulação de poder político faz com que a esfera pública afete o sistema político e seja por ele também afetada. Por meio da deliberação na esfera pública, articulam-se opiniões públicas que podem exercer influência sobre as instâncias decisórias do sistema político, mas não são dotadas de poder político propriamente. A influência gerada na esfera pública pode vir a transformar-se em poder comunicativo por meio dos filtros dos procedimentos democráticos institucionalizados. Esse poder comunicativo, por sua vez, pode ser convertido em poder administrativo do sistema político por meio de políticas públicas e programas sociais (HABERMAS, 1996, p. 362-363). No sentido oposto, os programas administrativos criam as condições necessárias para a existência das organizações da sociedade civil e, portanto, da própria esfera pública (Habermas, 1997a, p. 86-87).

De acordo com este modelo, a ênfase não está no resultado do processo democrático, mas na deliberação, na comunicação e nos procedimentos que regulam a participação 
e que possibilitam que a opinião pública discursiva alcance as instâncias decisórias. Opinião pública discursivamente gerada é dotada de "poder comunicativo" potencialmente capaz de constranger instâncias decisórias em uma determinada direção, permitindo-se assim sua conversão em "poder político-administrativo", por meio dos mecanismos do Estado Constitucional (HABERMAS, 1996, p. 354). Esferas públicas funcionam como amplificadores para os impulsos gerados no mundo da vida, que são filtrados, sintetizados e problematizados até que se tornem feixes de “opinião pública” capazes de alcançar as esferas de tomada de decisão do sistema político e influenciar publicamente as decisões políticas (HABERMAS, 1996, p. 360).

Habermas (1996, p. 354-357) recorre ao "modelo de comportas" de Bernard Peters para desenhar um modo de circulação de poder que atenda às pretensões comunicativas da ética do discurso. De acordo com esse modelo, o poder político circula em um eixo entre o centro (sistema político) e a periferia (esfera pública). O centro do sistema político, como uma poliarquia, é composto dos órgãos da administração, pelo sistema judicial e pelas instituições formais de formação da vontade política, que incluem o parlamento, as eleições políticas e a competição partidária. A capacidade de agir desses diferentes órgãos varia de acordo com a densidade administrativa. O parlamento, por exemplo, é o órgão mais adequado para identificar e tematizar problemas sociais, mas não tem a mesma capacidade de atuação dos órgãos da administração. Às margens do centro do sistema político, há uma espécie de periferia “interna”, constituída de instituições capazes de autoadministração ou de funções estatais delegadas tais como universidades, sistemas de seguros, fundações etc. A periferia “exterior”, a seu turno, é a esfera pública, com seus canais de comunicação informais e entrecruzados que permitem que os inputs gerados no mundo da vida possam ser tematizados e enfeixados na forma de opiniões públicas. Ao referir-se a esse modelo de circulação de poder, Fraser (1996, p. 125) fala de um "público fraco", cujas opiniões geram apenas influência, e um "público forte", a cujas opiniões vinculam-se sanções estatais.

Para ser legítima, assim, uma decisão política precisa ter sido informada pelos fluxos comunicacionais que começam na periferia e passam pelos filtros, ou "comportas", dos processos democráticos e constitucionais situados na entrada do complexo administrativo ou dos tribunais. Tal condição de legitimidade das decisões políticas torna-se relevante principalmente nos momentos de conflito. Na maior parte do tempo, as instituições do centro do sistema político seguem rotinas. Nos momentos em que se instaura um conflito, essas operações passam a ser problematizadas e

[...] a pressão da opinião pública consegue forçar um modo extraordinário de elaboração de problemas, que favorece a regulação da circulação do poder através do Estado de Direito, atualizando, portanto, sensibilidades em relação às responsabilidades políticas reguladas juridicamente.

(HABERMAS, 1997a, p. 86-87) 
O modelo habermasiano de circulação de poder explica como a esfera pública concomitantemente afeta e é afetada pelo sistema. No lado do input, a influência gerada na esfera pública é transformada por meio dos procedimentos democráticos das formação da vontade e opinião políticas, das eleições e da formação da opinião parlamentar, em poder comunicativo. Por sua vez, tal influência é transformada por meio de programas legais e diretrizes de corpos parlamentares em poder administrativo. No lado do output, são programas administrativos que criam as necessárias condições de existência da sociedade civil e das suas associações voluntárias e, portanto, de uma vibrante e política esfera pública. O conceito de sociedade civil no modelo habermasiano corresponde à dimensão mobilizada do mundo da vida (COHEN; ARATO, 1999).

A possibilidade de autodeterminação democrática e de realização dos potenciais emancipatórios da democracia depende do adequado funcionamento dessas comportas. Em cada uma dessas passagens - do mundo da vida para a esfera pública, da esfera pública para o sistema político e finalmente de volta à esfera pública e ao mundo da vida -, pode haver obstáculos à geração de poder comunicativo e à sua posterior conversão em poder administrativo legítimo. Formas de subordinação naturalizadas no mundo da vida pré-reflexivo, associadas por exemplo ao sexismo e racismo, nem sempre conseguem superar a primeira passagem e chegar à esfera pública para serem tematizadas. Da mesma forma, estruturas sociais como patrimonialismo, personalismo e clientelismo ilustram com clareza os obstáculos para que fluxos comunicacionais gerados no mundo da vida e tematizados na esfera pública transformem-se em políticas públicas. A saída, seguindo as premissas da ética do discurso, é transformar esses próprios obstáculos em temas de deliberação na esfera pública, esperando que um dia eles sejam dissolvidos, enquanto barreiras aos fluxos comunicacionais, pelo poder de argumentos racionais (HABERMAS, 1996, p. 22-23) (FRASER, 1996). Nesse ponto, a emergência de esferas públicas transnacionais podem ser úteis.

Para que os fluxos de comunicação gerados dentro da esfera pública se tornem opiniões públicas válidas, dotadas de influência política forte o suficiente para alcançar as instâncias decisórias do sistema, várias instituições devem estar presentes. Estas instituições fornecem respostas para questões fundamentais sobre esse tipo específico de comunicação capaz de gerar legitimidade política. Quem são os sujeitos de tal comunicação e quem são os receptores? Sobre o que eles estão comunicando? Por quais meios?

Nancy Fraser (2009, p. 79-80) lembra-nos que o modelo deliberativo supõe a existência de, pelo menos, seis instituições que foram concebidas originalmente no contexto de Estado-Nação: (a) um Estado soberano com jurisdição sobre um território delimitado e seus habitantes; (b) uma economia submetida à regulação do Estado; (c) uma cidadania que vive dentro do território nacional e tem interesses comuns; (d) uma língua nacional; (e) uma cultura nacional que possibilita o desenvolvimento e a reprodução de um senso de comunidade (nacional) imaginado e, assim, de uma identidade 
nacional; e (f) uma infraestrutura de comunicação: imprensa e mídia televisiva. Porém todas essas suposições institucionais precisam ser reavaliadas à luz da globalização e, com elas, a própria teoria da esfera pública.

\section{DESAFIOS PÓS-VESTFALIANOS ÀS PREMISSAS INSTITUCIONAIS DA ESFERA PÚBLICA}

Tanto na visão positivista de direito internacional quanto na realista de relações internacionais, hegemônicas no modelo de Vestfália, o Estado territorial constitui o único sujeito/ator político relevante na cena internacional. A única condição para o reconhecimento da soberania de um Estado é a verificação de um governo efetivo controlando o território nacional. Soberania, no clássico modelo vestfaliano, implicaria ao menos quatro outros corolários jurídicos: não intervenção, autodeterminação, jurisdição doméstica e igualdade entre Estados soberanos (KINGSBURY, 1998, p. 604-615). ${ }^{5}$

Influenciadas pelo conceito de Hobbes de Estado da natureza, ambas perspectivas teóricas presumem que a estabilidade na arena internacional só pode ser alcançada por meio do equilíbrio de poder entre Estados conflitantes, que são motivados somente, ou principalmente, por suas próprias raisons d’État. O direito internacional, neste contexto, é baseado ou na necessidade do estado de autopreservação, como no pensamento de Grotius, ou no interesse próprio de forma mais ampla, como na teoria de Hobbes. Desse marco analítico, resulta a afirmação do caráter primordialmente contratual do direito internacional, que coordena os interesses das partes envolvidas. O princípio pacta sunt servanda, assim, é o critério de legitimidade do direito internacional (WEILER, 2004, p. 555).

Não obstante, as noções de soberania absoluta e de Estado territorial, pedras angulares do sistema interestatal moderno, vêm sendo desafiadas no seu poder explicativo da realidade política contemporânea. ${ }^{6}$ A globalização, por cima, e o multiculturalismo, por baixo, estão destruindo o princípio da soberania territorial como critério para a clássica distinção entre assuntos internos e internacionais (GÓMEZ, 2000, p. 44). Na verdade, Estados rotineiramente têm de suportar as consequências das decisões tomadas fora da sua jurisdição ao mesmo tempo em que não são capazes de regular efetivamente uma série de atividades dentro de seus próprios territórios. A compressão espaço-tempo e as novas formas de interação afetam diferentes dimensões sociais de diferentes maneiras. As premissas institucionais da esfera pública mencionadas acima são transformadas em ritmos e a custos diferentes, gerando contradições cujas soluções ainda não foram encontradas (GÓMEZ, 2000; HELD, 1995).

Em vista desses problemas, extremistas afirmam o fim do Estado-Nação como locus de governança. Assumo, no entanto, o que Cohen chama de "tese fraca" sobre globalização, que reconhece o importante papel que o Estado moderno ainda desempenha na 
vida nacional e internacional, mas destaca a necessidade de uma revisão dos princípios do sistema interestatal moderno. Os Estados modernos são uma construção social moldada por circunstâncias históricas que foram profundamente alteradas nas últimas décadas. Na verdade, a noção de soberania absoluta de Vestfália sempre foi uma espécie de ficção, assim como hoje é exagerada a alegada perda da soberania (COHEN, 2003, p. 423; FALK, 1995, p. 165).

De acordo com este ponto de vista, não há nenhum indicativo de que a crise do sistema interestatal moderno represente o fim do Estado territorial, que ainda desempenha, por exemplo, o importante papel de mediador entre diferentes lealdades e identidades em níveis subnacional, nacional e transnacional (GÓMEZ, 2000, p. 31). O Estado, com efeito, ainda mantém importantes dimensões da soberania: faz guerras, sanciona o uso legítimo da força em seu território, protege cidadãos no exterior. Além disso, a cidadania plena em um Estado é uma "forma de filiação" muito importante, que confere privilégios importantes aos nacionais. Por último, os Estados ainda são os principais garantidores, assim como violadores, dos direitos humanos (COHEN, 2003, p. 423).

Na visão moderada de Anne-Marie Slaughter, a soberania não é absoluta nem é relativa, mas se tornou desagregada e não pode ser encontrada em um único locus institucional. Ela foi delegada a várias agências e entidades que operam em níveis diferentes (sub e supranacionais), sejam elas agências intergovernamentais ou fóruns políticos informais compostos de associações da sociedade civil, órgãos do Estado e agentes de mercado. Anne-Marie Slaughter (2004) destaca que, além das já conhecidas ações em rede por parte de organizações da sociedade civil, a relevância das redes formadas por autoridades estatais é crescente. Ministros, parlamentares, juízes e prefeitos, entre outros, estão se tornando cada vez mais organizados supranacionalmente. ${ }^{7}$ Para a autora, há diferentes tipos de redes governamentais, como redes de harmonização, de coação ou de informação, que exercem tanto o poder "duro" quanto o "leve". Tais poderes funcionam de modos diferentes, mas são ambos "poderosas" formas de se obter o que se quer: o primeiro opera por sanções positivas e negativas, e é baseado em uma teoria do comando; o segundo é baseado na "habilidade de convencer outros que eles querem o que você quer" (SLAUGHTER, 2004, p. 290).

Assumindo outra visão moderada, Jean Cohen (2003, p. 420) lembra-nos que há uma enorme variedade de instituições e práticas, privadas e públicas, sub e supranacionais, que dão origem a algum tipo de regulação ou autorregulação, contornando assim o Estado na geração de soft law. Como exemplos de tais instituições e práticas, Cohen cita as associações de comércio internacional, práticas normativas de advogados e de outros profissionais, arranjos internacionais de agências de cartão de crédito e franquias globais, bem como a Organização Mundial do Comércio, o Fundo Monetário Internacional e a União Europeia. Ainda que destituídas do caráter formal das normas de direito internacional, as normas de soft law podem, de fato, conformar condutas 
de atores importantes no cenário internacional. Em sua visão, há atualmente uma emergente ordem dualista:

Seu núcleo continua sendo a sociedade internacional de Estados soberanos, pluralisticamente segmentada, que cria direito internacional (via costumes e tratados) baseados no consentimento. Sobrepostos a isto há regimes jurídicos e politicos e IGGs [Instituições de Governança Global] dos subsistemas globais da sociedade mundial que são funcionalmente diferenciadas, e cujas estruturas institucionais, órgãos decisórios, e regras obrigatórias têm adquirido uma autonomia expressiva com relação aos seus Estados-membros e com relação uns aos outros. (COHEN, 2012, p. 311)

Cohen argumenta que esta ordem dualista do mundo está forjando uma diversa concepção de soberania, que não é a positivista monista, tampouco é a versão "desagregada", na medida em que "soberania é a reivindicação unificadora e autoidentificadora de um ente político relativamente à supremacia e à autonomia de sua ordem jurídica” e, como tal, é um importante referencial para a soberania popular. O discurso da soberania "unitária" guarda uma importância epistemológica, explicando a perspectiva interna, no sentido de Herbert Hart, dos agentes estatais em relação ao direito internacional e doméstico (COHEN, 2012, p. 1905). Na sua perspectiva, este novo regime de soberania caminha lado a lado com a emergência de um "pluralismo constitucional" que rompe com a dicotomia entre o constitucionalismo regional e o global. Cohen define o pluralismo constitucional como:

A pluralidade de fontes constitucionais de autoridades e de reivindicações concorrentes à supremacia jurisdicional de ordens jurídicas públicas (estatais e supranacionais), que são autônomas, mas que interagem e podem sobrepor-se. O relacionamento entre essas ordens jurídicas deve ser caracterizado como hierárquico, e gera um potencial para conflitos constitucionais que terão que ser resolvidos de uma maneira não hierárquica. (COHEN, 2012, p. 2020)

Em comum, a teoria da soberania desagregada e a do pluralismo constitucional criticam uma visão de ordem mundial baseada em um Estado monolítico. Sustentam a necessidade de um marco analítico que compreenda a pluralidade de grupos políticos agindo tanto no cenário doméstico quanto no supranacional, para defender interesses diversos. A clássica distinção vestfaliana entre assuntos domésticos e internacionais torna-se nebulosa, e não poderia ser compatibilizada com essas novas lentes, por meio das quais se enxerga a existência de numerosos novos atores, públicos e privados, operando no âmbito supranacional (SLAUGHTER, 2004). Cohen sustenta que a ideia de 
“governança," que gradualmente substituiu a de "governo", captura este movimento da ordem vestfaliana para a pós-vestfaliana:

O termo "governança" diz respeito a sistemas de regras que contam com mecanismos de controle consistentemente exercidos gerando aquiescência sistemática, prescindindo de uma autoridade política ou jurídica formal (um "governo") que seja necessariamente hierárquico. (COHEN, 2003, p. 446)

A tese moderada também implica a revisão da natureza nacional das outras instituições pressupostas no conceito de esfera pública. Além das noções de Estado-Nação territorial e de economia nacional, a concepção de cidadania ancorada na nacionalidade também deve ser revista. Habermas (1997) mostra em "cidadania e identidade nacional" como o nacionalismo representou historicamente uma fonte de solidariedade e integração social, contribuindo para a consolidação de um conceito ativo de cidadania. Mas ele argumenta que a ligação entre o nacionalismo e o Estado (evidenciada no termo Estado-Nação) é contingente, e não de conceitual. Com efeito, fenômenos, como migração em massa, diásporas, dupla cidadania, residência múltipla etc., tornaram-se cada vez mais intensos e frequentes, e, como resultado, não há mais nenhuma coincidência necessária entre cidadania, nacionalidade e território (FRASER, 2009, p. 88). Se, por um lado, a intensificação da migração aumentou a pluralidade dentro das fronteiras nacionais, por outro, também deu origem a movimentos nacionalistas e segregacionistas em reação à presença de imigrantes.

As outras três instituições (nacionais) implícitas na noção de esfera pública (nacional), quais sejam, língua nacional, infraestrutura nacional de comunicações e cultura nacional, também são problemáticas em tempos globalizados. De fato, pode-se adicionar a dispersão linguística à dispersão dos cidadãos. A intensificação do multiculturalismo na maioria das sociedades impede a afirmação de uma língua nacional. O número de países que adotam mais de um idioma oficial é grande e, provavelmente, ainda maior é o número de países que, embora reconhecendo apenas uma língua como oficial, tenha uma população que de fato fala diversas línguas. Da mesma maneira, a infraestrutura nacional de comunicações compete com uma profusão de mídias alternativas e redes sociais que são simultaneamente sub e supranacionais.

Por fim, culturas geograficamente delimitadas e nacionalmente definidas coexistem com uma hibridização crescente de influências e com a difusão de um entretenimento de massa americanizado. A pressão hegemônica da indústria do entretenimento de massa também desencadeou a resistência de culturas populares regionais e locais, que visam reforçar identidades regionais e locais vis-à-vis forças internacionais (FRASER, 2009, p. 90-91). Manuel Castells nota que "[...] expressões culturais são abstraídas da história e da geografia, e tornam-se predominantemente mediadas por redes eletrônicas de comunicação que interagem com o público em uma diversidade de códigos 
e valores" (2000, p. 80). Nenhuma dessas manifestações culturais pode ser entendida a partir de uma referência exclusivamente nacional. Ao contrário, elas destacarão o crescente pluralismo nas sociedades.

\section{Cosmopolitismo, realismo ou esferas públicas transnacionais?}

A crescente dissociação, causada pela globalização, entre aqueles envolvidos nos processos políticos de tomada de decisão e aqueles afetados pelas prováveis consequências de tais decisões resulta em um déficit democrático que é extremamente desconfortável para os que tentam recuperar o legado republicano de autodeterminação democrática (HABERMAS, 1999, p. 105-127). Tal desconforto motivou diversos projetos de democracia em nível global. Motivados pela expansão da democracia formal em todo o mundo na década de 1990 e inspirados pelo bicentenário do tratado de Kant (1991) sobre a paz perpétua, cosmopolitas em geral tentam replicar supranacionalmente modelos concebidos para um contexto doméstico. Tal arranjo institucional deve ser funcionalmente equivalente ao Estado-Nação e, como sua contrapartida nacional, deve ter um aparato burocrático administrativo legitimado democraticamente. Defendem a criação de mecanismos democráticos por meio dos quais os cidadãos do mundo (que também são cidadãos nacionais) e organizações internacionais da sociedade civil possam decidir questões (transnacionais) de interesse comum, atingindo os centros de tomada de decisão e obtendo um arranjo institucional - descentralizado ou não - que funciona como um Estado global. O respeito às diferenças culturais e peculiaridades locais, regionais ou nacionais seria mantido por meio da definição de diferentes níveis de governança, do local para o global, estabelecidos de acordo com o alcance do tema em discussão. ${ }^{8}$

Tais propostas não advogam necessariamente por uma República Mundial ou uma Federação Global, porém sustentam que uma governança pós-nacional sem um Estado pós-nacional é desejável, conquanto se mantenham as possibilidades da participação de cidadãos cosmopolitas em matérias de relevância global (SCHEURMAN, 2009 , p. 44). A versão deliberativa dessas propostas assume a desejabilidade de esferas públicas de alcance global e a efetiva participação daqueles cidadãos afetados pelas consequências das decisões. ${ }^{9}$ A proposta habermasiana da nova arquitetura democrática mundial envolve um sistema de três níveis - supranacional, transnacional e nacional - para os quais as funções tradicionais dos Estados seriam transferidas. Em um nível supranacional, uma Organização Mundial, uma ONU reformada, seria encarregada de assegurar a paz e implementar os direitos humanos pelo globo. Assuntos como meio ambiente, distribuição de recursos e respeito igualitário pelas principais culturas mundiais seriam discutidos em sistemas de negociações transnacionais, cujos marcos institucionais e a definição dos atores envolvidos ainda são inexistentes. Ele invoca a União Europeia como modelo para organizações transnacionais regionais capazes de 
realizar essas atribuições. Por fim, o nível nacional, mais próximo das bases sociais, assegura a fonte da legitimação democrática dessa sociedade global juridicamente constituída. De acordo com o autor, a necessidade de legitimação no nível supranacional só pode ser atendida com a emergência de uma esfera pública global e funcional, em que participam atores da sociedade civil mundial e cidadãos cosmopolitas. O destinatário da opinião pública global discursivamente gerada seria a Organização Mundial. A interação desses diferentes organismos e atores, no contexto do longo processo de aprendizado democrático, permitiria o surgimento de uma opinião pública informal capaz de suprir a remanescente necessidade de legitimação deste arranjo (HABERMAS, 2008, p. 445-451).

O reconhecimento de tendências democráticas no Pós-Guerra Fria, no entanto, não é suficiente para afirmar a viabilidade e a desejabilidade de proposta tão ambiciosa. O projeto de democracia cosmopolita continua utópico e inviável empiricamente. Falta-lhe potencial crítico, uma vez que não reconhece suficientemente as questões de poder e a desigualdade social, política e econômica como aspectos estruturais das relações internacionais. Subestima também as enormes dificuldades empíricas para implementação de arranjos institucionais em escala global que atendessem às suas exigências. Neste sentido, Cohen lembra-nos a frequência com que noções como "Estados falidos", "guerra preventiva" e "guerra ao terror" têm sido usadas recentemente para justificar projetos imperialistas que acarretam violação da igualdade soberana e dos direitos humanos:

Sob essa ótica, os discursos e práticas de intervenção humanitária ou democrática, as ocupações transformativas, as sanções direcionadas, as listas negras de terroristas e a dramática expansão sobre seus poderes diretivos e legislativos pelo Conselho de Segurança, na sua luta contra o terrorismo global, [...] são mecanismos que promovem a desformalização do direito internacional existente, e permitem aos muito poderosos [...] criarem regras globais e princípios de legitimidade autointeressados. (COHEN, 2012, p. 278)

Do ponto de vista da teoria democrática, Dahl (1999) argumenta a impossibilidade da democracia cosmopolita à luz da inexistência de um demos global, e de um senso comum de pertencimento e comunidade que se materialize em uma linguagem comum, uma religião comum e traços culturais comuns. E ainda, de acordo com o autor, temos um problema empírico: quanto maior for a comunidade considerada, mais diversa ela será, e a “[...] diversidade, por sua vez, tende a aumentar o número de possíveis interesses políticos e de clivagens baseadas nas diferenças de posições econômicas, linguagem, religião, identidade étnica ou racial, cultura, afiliação nacional, memórias históricas, ligações organizacionais, entre outros" (DAHL, 1999, p. 26). ${ }^{10}$ 
A inexistência de um demos global transformaria perspectivas cosmopolitas em projetos potencialmente autoritários (DAHL, 1999) (WEILER, 2004). Dahl afirma que a ordem internacional está longe de ser democrática em qualquer sentido:

[...] devemos ser cautelosos ao ceder a legitimidade da democracia para sistemas não democráticos. No decurso deste século, nós já testemunhamos muitas tentativas de encobrir sistemas não democráticos no manto da democracia. [...] Todos estes foram na verdade formas não democráticas de regimes burocráticos, hierárquicos ou autoritários. Se as organizações internacionais não são democráticas, não somos obrigados a falar a verdade sobre elas? (1999, p. 33-34)

Os atuais desafios para as sociedades e os governos de países centrais e periféricos são substancialmente diferentes, apesar de terem as mesmas origens nos processos de globalização e multiculturalismo. Para países periféricos, a distinção entre assuntos internos e internacionais nunca foi clara, e a ideia de autodeterminação soberana sempre foi utópica. Nesse sentido, arranjos globais democráticos poderiam aumentar a sua capacidade de autodeterminação e de influência nos processos decisórios globais. No entanto, governos de países hegemônicos rejeitam soluções derivadas da democracia para questões coletivas globais, pois da perspectiva estrita da raison d'État daqueles que detêm poder efetivo no cenário internacional, a democratização e uma clara definição dos vários níveis de governança podem representar perda ou redução da sua capacidade de controle da política internacional. Da mesma forma, cidadãos desses Estados temem que arranjos cosmopolitas os afastem das instâncias decisórias. Assim, de um ponto de vista estritamente prudencial, realista, não é do interesse de governos e sociedades de países centrais promover as mudanças necessárias para uma democracia deliberativa cosmopolita.

Voltando aos critérios de Fraser, entendo que há problemas relativos tanto à legitimidade democrática quanto à eficácia política de projetos cosmopolitas. Não há clareza quanto ao público forte global cujas decisões terão eficácia política. Seriam as organizações internacionais? Ou seriam os Estados, que constantemente bloqueiam as negociações importantes e depois receberiam o encargo de implementar internamente as decisões globais “democráticas”? Tampouco há clareza quanto ao público fraco que deverá participar dessas mobilizações de modo a conferir legitimidade normativa às opiniões públicas globais: quem são as ONGs que participam da política internacional em nome do cidadão do mundo? Quem as financia? Quem define a pauta? Quais assuntos são de interesse global? Fraser (2009, p. 48-77) ressalta a importância dessas questões de "enquadramento" na globalização, ainda sem solução institucional.

No entanto, apesar dos desafios apontados para um novo modelo de governança cosmopolita, transformações recentes já consolidaram esferas públicas transnacionais 
que poderiam funcionar como arenas adicionais, por meio das quais os cidadãos nacionais veriam suas demandas discutidas pelo sistema político nacional. Concordo com a afirmação de Kathryn Sikkink de que

esta alternativa parcial [ao modelo de Vestfália] não é uma nova entidade, mas sim uma rede multinivelada de diversas entidades que coordenam atividades na área das questões dos direitos humanos... essa rede é composta por uma série de organizações e práticas, algumas formais, outras informais, que de forma gradual e hesitante, complementam e competem com a doutrina tradicional da soberania e com a noção de divisão rígida entre relações internacionais e política nacional. (SIKKINK, 1991, p. 4-5)

As características centrais deste novo cenário são o espessamento das dimensões constitucionais e regulatórias do direito internacional e o crescente papel da sociedade civil na vida internacional, tanto nos processos formais e informais de tomada de decisões quanto na participação direta em atividades governamentais, como ajuda humanitária e reconstrução social e política pós-conflito. A seguir, discutirei as transformações que possibilitaram a identificação de esferas públicas transnacionais: a criação de regimes internacionais de direitos humanos e das respectivas organizações internacionais que proporcionam bases institucionais para esferas públicas transnacionais, e o surgimento de organizações da sociedade civil transnacionais, articuladas na forma de redes.

\section{Transformações No DiReito INTERNACIONAL}

De acordo com Joseph Weiler, o "processo de legislação” internacional era predominantemente bilateral e contratual. O recurso ao direito internacional consuetudinário consistia em uma "prática de olhar para trás", que flagrantemente privilegiava o status quo (WEILER, 2004, p. 549). Nesse mundo de relações horizontais entre Estados soberanos, já havia algumas instituições e organizações multilaterais, como a União Postal, mas essas eram "em substância apenas estruturas mais eficientes permitindo aos Estados-partes negociar acordos bilaterais" (WEILER, 2004, p. 553).

Weiler afirma que a principal característica do direito internacional do final do século XX é o espessamento do que ele chama de "camadas" constitucionais e regulatórias do direito internacional, sem que isso significasse o desaparecimento das suas dimensões "contratuais". O espessamento dessas camadas afeta tanto o processo legislativo quanto os métodos de resolução de litígios e está associado a duas preocupações relativamente recentes: primeiro, o reconhecimento dos valores universais (presente na Carta das Nações Unidas, no Tratado da União Europeia e em vários tratados internacionais de direitos humanos, por exemplo) e, segundo, a gestão mais eficiente 
de questões transnacionais e os desafios que enfrentamos hoje como membros de uma sociedade não voluntária de riscos globais (como os presentes no comércio mundial, no regime financeiro global e no meio ambiente). Ambas as camadas avançam um conceito de direito internacional "vertical" que limita explicitamente a soberania do Estado, criando regimes e organizações internacionais. ${ }^{11}$ Nesta seção, pretendo tratar das inovações trazidas por cada uma dessas camadas, dando destaque à importância do regime internacional de direitos humanos e à nova relevância das organizações internacionais.

A dimensão constitucional do direito internacional apresenta um "modo de comando" diferente: deixa de ser meramente transacional e denota o surgimento de um senso de comunidade existente em algumas áreas da vida internacional. Como Weiler explica, "materialmente, a marca da comunidade pode ser encontrada na apropriação ou definição de bens comuns", que podem ser materiais (o leito profundo do alto mar ou as áreas do espaço, por exemplo) ou espirituais (como o direito internacional dos direitos humanos ou a ecologia). Em consonância, as novas organizações internacionais como a ONU, a OEA e a UE, que proliferaram depois da década de 1950, articulam objetivos que em parte são distintos dos objetivos específicos de seus Estados membros (Weiler, 2004, p. 556) A soberania estatal cede a uma regulação internacional que protege valores considerados universais.

Dentre as matérias típicas dessa camada constitucional, direitos humanos desempenham um importante papel na criação de esferas públicas transnacionais. Os direitos humanos internacionais asseguram direitos a todo ser humano, não importando sua nacionalidade (HELD, 2000, p. 167). No período pós-guerra, indivíduos eram inicialmente vistos como objetos de proteção do direito internacional contra abusos cometidos por agentes do Estado, antes abrigados pelo princípio da soberania absoluta. Gradualmente, contudo, indivíduos e “cidadãos globais” tornaram-se agentes na arena internacional, participando de modo formal ou informal. Indivíduos, grupos de indivíduos e organizações não governamentais são autorizados, por exemplo, a iniciar procedimentos contra os Estados. Eles podem oferecer pareceres como amicus curiae em várias cortes internacionais. Diversas organizações não governamentais têm status consultivo em organizações internacionais e exercem uma forte influência política em importantes esferas de tomada de decisão. O regime internacional dos direitos humanos possibilitou importantes plataformas de lutas bem-sucedidas em direção à ampliação da proteção jurídica aos indivíduos. O regime de direitos humanos também permitiu o surgimento de uma nova linguagem compartilhada, na qual foi possível a criação de novas identidades.

A camada regulatória do direito internacional adensa-se ao final do século XX, e refere-se a assuntos tradicionalmente nacionais, como meio ambiente, finanças, comércio e saúde, que, em razão de diferentes processos de globalização, adquirem dimensão transnacional e não podem mais ser adequadamente tratados de forma exclusiva 
por instituições nacionais. Novamente, a obsolescência da divisão tradicional entre assuntos nacionais e internacionais torna-se evidente. As novas normas regulatórias do direito internacional criam obrigações diretas para indivíduos e mercados, que muitas vezes substituem as nacionais. Weiler nota que "o regime de regulação é muitas vezes associado a um mecanismo burocrático internacional, com funcionários civis internacionais e agentes estatais de nível médio como interlocutores" (WEILER, 2004, p. 558). A existência de uma burocracia permanente, que não havia antes, possibilita uma resposta mais rápida a crises e facilita o desenvolvimento de assistência técnica e de projetos de cooperação científica (HERZ; HOFFMANN, 2004, p. 20).

Weiler afirma que essas mudanças normativas são acompanhadas por mudanças nos mecanismos de solução de controvérsias, que também se tornam mais verticalizados e judicializados e menos dependentes da diplomacia. ${ }^{12} \mathrm{Com}$ efeito, enquanto a jurisdição dos órgãos de fiscalização constitucionais criados no despertar da Segunda Guerra Mundial, como a Corte Interamericana de Direitos Humanos (CIDH) ou os diversos organismos de monitoramento da ONU, tiveram de ser explicitamente reconhecidos pelos Estados-Membros, o caráter vinculante das decisões tomadas por mecanismos regulatórios de solução de controvérsias, como o da Organização Mundial do Comércio, estabelecidos em tratados mais recentes, é automático (WEILER, 2004, p. 558).

A importância da criação de organizações internacionais e de regimes constitucionais e regulatórios pode ser avaliada a partir de diferentes perspectivas. Realistas afirmam que instituições internacionais refletem e reproduzem as relações de poder que caracterizam assuntos internacionais. Institucionalistas liberais, por sua vez, enfatizam que instituições internacionais são cruciais porque elas ajudam na solução de problemas de coordenação da ação coletiva na arena internacional. De um ponto de vista liberal construtivista, no entanto, as instituições fazem mais do que realistas e institucionalistas admitem; as instituições internacionais ajudam-nos a compreender como as novas regras são criadas e difundidas no sistema internacional e posteriormente internalizadas por diferentes atores (SLAUGHTER, 1993). Hurrel exemplifica este argumento, dizendo que "as instituições internacionais podem ser o local onde as autoridades brasileiras e argentinas, por exemplo, são expostas a novas normas” (HURRELL, 2001a, p. 37).

Organizações internacionais são locais para negociação e deliberação e, simultaneamente, atores centrais na esfera internacional, dotados de personalidade jurídica reconhecida pelo direito internacional e relativamente autônomas em relação aos Estados-Membros. Essas instituições fornecem a base para fóruns deliberativos onde interesses e pontos de vista são expressos e podem ser alterados no curso de negociação.

Os Estados podem não saber o que querem quando começam a negociar questões complexas dentro de complexos quadros institucionais ou podem 
mudar suas ideias durante o processo, o que possibilita entendimentos revisados sobre interesse nacional. (HURRELL, 2001a, p. 37)

A criação de regimes relacionados a organizações internacionais podem promover estabilidade e conformidade com o direito internacional de três maneiras. Em primeiro lugar, regimes criam um tipo de reciprocidade difusa que promove a ação coletiva: quanto maior a expectativa de que todos os Estados-Membros vão respeitar um determinado conjunto de regras, maior é o incentivo para que cada ator cumpra as mesmas regras. Em segundo lugar, as organizações internacionais podem aumentar a legitimidade das normas relativas aos regimes e desenvolver um senso de dever moral de obedecer à lei. Por último, organizações internacionais, em algumas circunstâncias, podem impor suas decisões aos Estados desviantes por meio de pressão política, sanções e até força militar (HERZ; HOFFMANN, 2004, p. 24).

O desenvolvimento de regimes internacionais altera o equilíbrio de poder na medida em que cria uma forma de "legalidade internacional". Fornece fóruns especiais de deliberação e cria várias possibilidades para a participação de atores mais fracos de acordo com a sua "capacidade de usar as plataformas institucionais e de explorar parâmetros jurídicos já estabelecidos para promover decisões e instituições novas e de maior alcance" (HURRELL, 2001a, p. 38).

\section{REDES TRANSNACIONAIS E ESFERAS PÚBLICAS}

Além da relevância crescente de organizações internacionais no direito e na política internacional, o surgimento de organizações da sociedade civil como novos atores transnacionais é fundamental para a constituição de esferas públicas transnacionais. $\mathrm{Na}$ verdade, é importante destacar o papel que os atores da sociedade civil vem desempenhando no cenário internacional, influenciando a agenda e prestando serviços:

[...] primeiro, no processo formal de criação, consolidação e desenvolvimento de normas; em segundo lugar, no amplo processo social pelo qual novas normas emergem e encontram seu caminho para a agenda internacional; terceiro, no funcionamento detalhado de muitas instituições internacionais e no processo de implementação e cumprimento; e, finalmente, na participação direta em muitas atividades governamentais (desembolsando uma proporção crescente de ajuda oficial, engajando em ajuda humanitária de grande escala; liderando esforços para promover a democracia ou a reconstrução social e política pós-conflito). (HURRELL, 2001a, p. 32) ${ }^{13}$

A infraestrutura física e tecnológica (incluindo transporte e comunicação) de uma economia cada vez mais conectada facilitou a circulação de valores, conhecimento e 
ideias (HURRELL, 2001a) De fato, se a tecnologia criou novas ameaças às sociedades contemporâneas, como enfatizado por Ulrich Beck e outros, também criou novos padrões de comunicação, promovendo uma pluralidade de novos públicos, que compartilham "relatórios e informações, chamadas telefônicas, participação em reuniões, ou fluxos de financiamento" (SIKKINK, 1991). Essas inovações tornaram possível o desenvolvimento de uma nova espécie de "repertório de ação" para ser usada pelos movimentos sociais, tais como petições online, campanhas de e-mail, marchas virtuais, e assim por diante. Elas têm aumentado a capacidade de mobilização coletiva e do surgimento de "novas formas de conexão social, novas formas de ação coletiva e uma 'solidariedade entre estranhos' mais extensa" (COHEN, 2003, p. 435). ${ }^{14}$ Assim como organizações internacionais, a sociedade civil fornece uma arena importante para o processo de socialização, difusão e internalização de normas (HURRELL, 2001a, p. 34).

A forma por excelência dos novos modos transnacionais de associação, como já mencionado, são as redes, que podem ser definidas como

estruturas comunicativas das quais participam atores situados em diferentes posições com a finalidade de influir nas políticas públicas, nas normas, e nos procedimentos decisórios de entidades muito poderosas, e também nas quais negociam o significado de seu próprio empreendimento. Esses atores fazem uso de padrões horizontais de comunicação e de troca que permitem uma agência que é mais do que a soma das suas partes (COHEN, 2003, p. 435).

Sikkink destaca como modo típico de associação e mobilização no mundo pós- vestfaliano as redes articuladas em torno de questões de direitos humanos, que são formadas não somente por atores da sociedade civil, mas também por atores sistêmicos, e tornam-se uma alternativa parcial ao modelo interestatal, centrado na noção de soberania absoluta do Estado. Essas redes incluem organizações internacionais, organizações não governamentais internacionais, organizações não governamentais nacionais, e órgãos de governos encarregados dos temas de direitos humanos. Ainda que haja tensões importantes, essas redes são formadas por atores que partilham de entendimentos relativos ao direito internacional que permitem uma linguagem comum para apresentar argumentos e conjuntos de procedimentos para avançar reivindicações (SIKKINK, 1991, p. 415).

Sikkink (1991, p. 38) também enfatiza que as relações entre os diferentes atores reforçam-se mutuamente, embora não necessariamente de forma amigável. As dinâmicas que se desenrolam no âmbito dos litígios perante os órgãos do Sistema Interamericano de Direitos Humanos (SIDH) ilustram o argumento. Peticionários (vítimas e organizações da sociedade civil brasileira e internacional), funcionários da Comissão e da Corte e funcionários dos órgãos de representação internacional dos Estados 
(Itamaraty, Secretaria de Direitos Humanos da Presidência da República, e Advocacia-Geral da União, no caso brasileiro) fazem parte de uma mesma rede, repleta de tensões e de entendimentos que já produziram transformações importantes internamente, vis-à-vis nossa política de enfrentamento à violência doméstica, ao trabalho escravo e à brutalidade policial (BERNARDES, 2011).

O conceito de redes de direitos humanos, por um lado, explica os desenvolvimentos transnacionais que afetam a sociedade civil; por outro lado, capta a ideia de soberania desagregada, na medida em que essas redes incluem "partes de governos". Dos vários atores e burocracias do sistema político, alguns pertencem a essas redes e, para usar a linguagem do modelo de Peters, podem funcionar como "comportas" entre as esferas públicas transnacionais e os sistemas políticos dos Estados, ou entre a "periferia" e o "centro", respectivamente.

A relação dialética entre o local e o global, típica do nosso tempo globalizado, também se reflete em tais redes. De acordo com a descrição de Sikkink, as redes às vezes trabalham de forma a "internalizar" atores externos, que se tornam influentes nos processos políticos nacionais; em outros momentos, funcionam para "internacionalizar" questões de política interna, "como quando as práticas de direitos humanos dos Estados-Membros são discutidas nas reuniões de organizações regionais e internacionais" (SIKKINK, 1991, p. 7-8). Elas podem atuar em diferentes níveis, deslocando a discussão de fóruns internos para fóruns transnacionais, e vice-versa, de acordo com as circunstâncias. Por um lado, as articulações internacionais de uma rede geralmente são mais capazes do que os seus componentes nacionais de atrair a atenção para um tema específico; por outro, organizações de base e demais articulações internas das redes transnacionais mostram maior capacidade de gerar solidariedade e níveis mais intensos de mobilização, porque se baseiam na interação face a face. (COHEN, 2003).

No lado da saída (output), os destinatários das interações comunicativas que ocorrem nas esferas públicas transnacionais são múltiplos, gerando os problemas de enquadramento anunciados por Fraser. Podem ser "Estados, organizações internacionais, órgãos políticos, e organizações privadas em níveis local, regional e transnacional" (SIKKINK, 1991, p. 18). Na verdade, as redes às vezes buscam estratégias que visam, principalmente, políticas e estruturas normativas de organizações internacionais, como a campanha contra os programas de ajustamento estrutural do FMI, ou o lobby ambiental ante a OMC. Nesses casos, pode-se ver uma opinião pública mundial, ainda embrionária e intermitente, mobilizada principalmente por meio de grandes organizações não governamentais e com o objetivo de ter um impacto em termos de governança global. No entanto, ainda há pouca clareza de quem seja o destinatário das reivindicações formuladas, diante da inexistência de uma institucionalidade cosmopolita eficiente, como já mencionado.

Não pretendo tratar do "problema de enquadramento" neste artigo. Interesso-me pelo que Keck e Sikkink chamam do padrão bumerangue de influência, onde o alvo 
principal da mobilização é o Estado territorial, cujas políticas ainda são as que afetam mais diretamente a vida das pessoas (KECK; SIKKINK, 1998, p. 12). Em algumas circunstâncias, quando os fluxos de comunicação são bloqueados, organizações da sociedade civil se dirigem a organizações internacionais, que, por sua vez, exercem pressão sobre o Estado em questão:

Quando os canais entre o Estado e seus atores domésticos são bloqueados, as características do modelo bumerangue de influência das redes transnacionais podem ocorrer: ONGs nacionais contornam seu Estado e buscam diretamente aliados internacionais para tentar trazer pressão de fora para seus Estados. [...] quando os governos são inacessíveis ou surdos para grupos cujas reivindicações podem, contudo, ressoar em outros lugares, contatos internacionais podem amplificar as exigências dos grupos domésticos, intrometer-se em espaços abertos para novas questões, e então ecoar de volta essas demandas na arena nacional (KECK; SIKKINK, 1998 , p. $12-13) \cdot{ }^{15}$

A formação de redes de direitos humanos cria diferentes possibilidades de aumentar a influência política gerada por meio de deliberações em esferas públicas. As associações entre atores transnacionais e de base são de duas naturezas: por um lado, este tipo de associação pode ajudar a difundir valores como igualdade racial e de gênero. Atores transnacionais podem ajudar as organizações de base a desenvolver uma linguagem por meio da qual elas possam vocalizar suas necessidades. Assim, elas podem catalisar o processo de trazer problemas do mundo da vida para a esfera pública, tematizando formas de dominação que foram antes naturalizadas e relegadas à esfera privada pré-reflexiva. Atores transnacionais também podem fornecer financiamento e apresentar novas formas de mobilização que passam a integrar os repertórios das organizações sociais de base. Por outro lado, em uma perspectiva de baixo para cima, ao transnacionalizar questões locais que não são tratadas de forma adequada internamente - tanto porque permanecem temas de interesse exclusivo de públicos subalternos e não alcançam esferas públicas mais abrangentes quanto porque os atores do sistema político resistem em levar em consideração a opinião pública gerada comunicativamente -, as redes aumentam sua visibilidade, levando ao conhecimento de outros públicos, nacionais e transnacionais, e ampliando as possibilidades de formar uma opinião pública comunicativa mais forte sobre este tipo de tópico. A intenção é mostrar que Estados que formalmente assumiram obrigações relativas aos direitos humanos e à democracia violam rotineiramente seus compromissos. Isso, por sua vez, pode ter o efeito de "educar" atores estatais a respeito das suas obrigações internacionais e dos problemas internos, permitindo que funcionem como "comportas" por meio das quais a opinião pública comunicativa atinge o centro do sistema político. 
De acordo com Cohen, existem quatro aspectos da publicidade envolvidos nos processos descritos acima, cada um dos quais mesclando elementos comunicativos e estratégicos:

[...] política de informação, cuja condição necessária é a capacidade de gerar de modo rápido e confiável informações políticas mobilizáveis nas situações em que tentam máxima eficácia, uma política simbólica, ou o recurso a símbolos e narrativas que explicam a lógica de uma situação para públicos locais e distantes; uma política de influências ou de interesses [leverage politics], ou a capacidade de apelar a atores poderosos para influir em uma situação em que membros mais fracos de uma rede têm pouca influência; e uma política de responsabilização, isto é, o esforço para fazer com que atores poderosos respeitem os princípios acordados previamente no plano nacional ou no plano da opinião pública mundial. (COHEN, 2003, p. 440)

Além disso, ao contrário da sociedade civil nacional, que na perspectiva teórico discursiva só pode gerar influência sobre o sistema político, na sociedade civil transnacional, "a política de influência é complementada pela utilização de algumas formas de poder" (COHEN, 2003, p. 442 - grifo meu) O fato de que as organizações internacionais podem ser mobilizadas por redes transnacionais dá origem a um "poder de constrangimento": o poder de envergonhar determinados países ante seus pares em organizações internacionais por violarem os padrões internacionais de direitos humanos que formalmente se comprometeram a assegurar. No entanto, é importante observar o elemento normativo de tal "poder de constrangimento". A “vergonha” de um país só é possível porque existem padrões normativos que são aceitos como válidos e universais. Existe um aspecto performativo do reconhecimento internacional da obrigação de respeitar e garantir direitos humanos que gera uma contradição profundamente desconfortável para Estados denunciados como violadores de normas de direitos humanos.(LAFONT, 2012)

A participação de organizações internacionais, como os órgãos de proteção de direitos humanos da OEA, obriga os Estados, ou pelo menos os órgãos encarregados de sua representação internacional, a responderem a reclamações de organizações da sociedade civil que, normalmente, ignorariam. Alguns desses órgãos nacionais tornam-se interlocutores importantes das organizações da sociedade civil e acabam exercendo ativamente o papel de criar, dentro do sistema político, a possibilidade de reforma de políticas de acordo com as opiniões públicas discursivas. Em alguns casos, esses órgãos funcionam como comportas entre a esfera pública e o sistema mais eficazes do que o judiciário e o parlamento, aos quais Peters e Habermas originalmente atribuíram esta função. (HABERMAS, 1996, p. 352-359) 
Mas esses processos, contudo, são ainda desenvolvimentos embrionários com toda sorte de deficiências. Especificamente sobre a participação de organizações da sociedade civil, há sérios problemas de legitimidade e responsabilização, uma vez que são, por definição, entidades não eleitas, usualmente baseadas em Estados ocidentais centrais, interferindo no processo político em nome do cidadão global. O potencial para instrumentalização e uso estratégico da opinião pública transnacional para legitimar práticas questionáveis é evidente. Da mesma forma, as "redes" são uma forma de organização que pode servir a diferentes propósitos: de mobilização legítima da sociedade civil a ataques terroristas (COHEN, 2003, p. 437). E, ainda, organizações internacionais são, elas mesmas, espaços de poder, e não podem ser vistas como arenas de livre discussão sem constrangimentos de poder outros que o do melhor argumento. De fato, são os grupos hegemônicos que estabelecem a agenda, as regras do jogo e mesmo os jogadores (HURRELL, 2001a, p. 37). Cohen também nos recorda que as novas formas de governança estão imbuídas de um "ethos corporativo": elas não são transparentes, não são internamente democráticas e não prestam contas a terceiros. Contudo, concordo com a ênfase de Cohen no fato de que tais críticas não passam incontestes pelas múltiplas novas formas globais de interação: “cada nova forma de exclusão e instrumentalização da nova mídia provoca lutas por inclusão e hegemonia, acesso e democratização" (COHEN, 2003, p. 441).

\section{CONCLUSÃo}

Uma das características do conceito de esfera pública, como enfatizado por Nancy Fraser, é a pluralidade. Em vários níveis, do local ao global, existem distintas esferas públicas que se sobrepõem. O surgimento das esferas públicas transnacionais, que processam inputs da sociedade civil, de organizações internacionais, de agentes do mercado e de funcionários do Estado, foi possibilitado em razão de transformações políticas e jurídicas, assim como a importantes inovações tecnológicas, que facilitaram a comunicação e mobilização em nível global. De fato, a crescente relevância da sociedade civil transnacional e das organizações internacionais criaram novos modos de interação no âmbito supranacional que diferem da relação contratual entre os Estados, típica do modelo vestfaliano.

Tais transformações na arena supranacional impactaram as discussões sobre governança global, mas elas também tiveram um efeito bumerangue ao transformar políticas internas em países diferentes. O surgimento de esferas públicas transnacionais complementa as estruturas internas e cria novos modos por meio dos quais temas são retirados do mundo da vida e se tornam tópicos de discussão pública. Essas esferas públicas também criaram novas formas de gerar influência e algumas formas de poder que aumentam as chances de o sistema político levar a opinião pública em consideração. 


\section{NOTAS}

* A autora agradece a Liam Murphy, Andrew Arato, David Golove, Adeeno Adis, Larry Lee, Florian Hoffmann, Gisele Cittadino, José Maria Gomez, Carolina de Campos Melo pela leitura crítica a versões preliminares deste artigo, no processo de produção da tese de doutorado. Agradece também a Simone Pitta, Natalia Frickmann e Mariana Braga pela tradução de trechos deste artigo que estavam originalmente em inglês.

1 O chamado modelo de Vestfália foi usado durante mais de 300 anos para explicar as relações internacionais e o direito internacional do chamado sistema interestatal moderno. O nome alude à Paz de Vestfália, um conjunto de tratados que pôs fim, em 1648, à Guerra dos Trinta Anos na Europa. Voltaremos a discuti-lo na seção seguinte deste artigo.

2 Como um exemplo de tal esforço, em Scales of justice, Nancy Fraser (2009) discute qual seria o melhor princípio para enquadrar nossas questões na justiça global. De forma similar, Jean Cohen (2012), em seu livro Globalization and sovereignty, reflete sobre as implicações das novas constelações pós-nacionais nos conceitos de soberania e legalidade. Este não é meu objetivo no trabalho ora apresentado, contudo. Preocupo-me aqui com a política doméstica via estratégias transnacionais.

3 Minha tradução. Na página 211, Power (1998) afirma que "Há realmente uma certa trágica inevitabilidade no fato de que, uma vez que o problema da autofundamentação é colocado, a teoria crítica necessariamente fica comprometida em uma de duas direções: ou ela retém a sua força crítica às custas da sua autofundamentação, ou ela amortece os termos da sua crítica a fim de preservas a possibilidade de autofundamentação".

4 O conceito de mundo da vida, de inspiração fenomenológica, refere-se ao estoque de conceitos e visões de mundo que são tomados como dados em nossa vida cotidiana. É a informação de pano de fundo que torna a comunicação possível. O sistema, por sua vez, refere-se ao reino das relações sociais que se tornam autônomas do pano de fundo do mundo da vida e que se reproduzem de modo autômato através de meios reguladores, tais como dinheiro e poder. Ver Habermas (1985).

5 Enquanto o positivismo enfatiza a igualdade formal dos Estados soberanos, o realismo foca nas questões de poder que movimentam as relações inter-nacionais, sem que essas peculiaridades constituam incompatibilidades entre as teorias. De fato, Benedict Kingsbury ressalta que, apesar da centralidade que confere à noção de soberania, o positivismo reconhece a existência de assimetrias entre nações, rotulando-as como "políticas", em vez de "legais". Na verdade, positivistas, como Oppenheim, podem ter pontos de vista realistas quando se trata de preservar a estabilidade da ordem mundial (KINGSBURY, 1998, p. 604-615).

6 Alguns autores defendem a necessidade de uma redenção normativa do princípio da soberania absoluta como um escudo contra as ameaças da globalização. Para eles, levando-se em consideração as assimetrias entre e Norte e Sul globais, soberania e não intervenção funcionam como as principais defesas dos países periféricos (KINGSBURY, 1998, p. 599-625).

7 Manuel Castells (2000) enfatiza também que a mais nova fase da economia capitalista também tomou a forma de redes.

8 Para propostas cosmopolitas, ver ARCHIBUGI \& HELD, 1995. Sobre níveis de governança, ver especialmente Held (1995).

9 Nancy Fraser poderia ser incluída aqui com ressalvas. Por um lado, ela se ocupa dos problemas de justiça global, que requerem uma nova forma de "enquadrar" demandas de justiça. Propõe o "princípio de todos subjugados", de evidente inspiração cosmopolita no sentido acima descrito. Por outro lado, ela está consciente dos obstáculos da realpolitik para o estabelecimento de novos arranjos que permitiriam a implementação do seu princípio de justiça e reconhece que os arranjos institucionais para que isso se realize ainda precisam ser criados (FRASER, 2009, p. 48-75).

10 É claro que esse argumento pressupõe que, para Dahl, existiria demos em níveis nacionais. Como vimos, no entanto, esse argumento é problemático diante das muitas diásporas e dispersões linguísticas e culturais.

11 De acordo com a definição clássica de Stephen Krasner (1982, p. 1), regimes são um conjunto de princípios, normas, regras e procedimentos de tomada de decisão em torno do qual as expectativas dos envolvidos convergem. Ver 
também Herz \& Hoffmann (2004, p. 20). Weiler aponta, entretanto, que mesmo a lei bilateral, transnacional, internacional cria regimes multilaterais e pode funcionar como uma forma de governança, embora de forma mais indireta. Atores poderosos como EUA e Europa desenvolvem "moldes" que são impostos aos seus parceiros, que possuem muito pouco espaço para negociação. Ele é igualmente cético quanto às possibilidades de uma ordem democrática internacional, por não haver um demos global. Ver Weiler (2004, p. 561).

12 Para um relato compreensivo da proliferação de sistemas triádicos de resolução de litígios e uma mapeamento do judiciário internacional, ver Romano (1999, p. 709-52).

13 Porém é importante notar que, enquanto Hurrell observa essas tendências, ele mesmo não é proponente da democracia global.

14 Sobre o conceito de "repertório social”, ver Tilly (2004).

15 No ano seguinte, Risse, Ropp e SIkkink (1999) falam de um "modelo espiral” para promoção de políticas públicas domésticas mais compatíveis com os direitos humanos. O aspecto "espiralado" diz respeito à necessidade de se “jogar o bumerangue" diversas vezes até que a resposta do Estado demonstre incorporar as demandas internas. Ver também Risse, Ropp e SIkkink (2013).

\section{REFERÊNCIAS BIBLIOGRÁFICAS}

ARATO, Andrew. Procedural Law and Civil Society: Interpreting the Radical Democratic Paradigm. In:

ROSENFELD, Michael; ARATO, Andrew (Eds.). Habermas on law and democracy. Berkley and Los Angeles: University of California Press, 1998.

ARCHIBUGI, Danielle. The global commonwealth of citizens: toward cosmopolitan democracy. Princeton: Princeton University Press, 2008.

. From the United Nations to Cosmopolitan Democracy. In: ARCHIBUGI; HELD (Eds.). Cosmopolitan democracy: an agenda for a new world order. Cambridge: Polity Press, 1995.

AVRITZER, Leonardo. Democracy and the public space in Latin America. Princeton: Princeton University Press, 2002. BAUMAN, Zigmunt. Globalização: as consequências humanas. Rio de Janeiro: Jorge Zahar, 1999.

BECK, Ulrich. What is globalization? In: HELD, David; McGREW, Anthony. The global transformation reader: an introduction to the globalization debate. Cambridge: Polity Press, p. 99-104, 2000.

BERNARDES, Marcia Nina. O sistema interamericano de direitos humanos como esfera pública transnacional: aspectos jurídicos e politicos da implementação de decisões internacionais. SUR - Revista Internacional de Direitos Humanos, v. 8, n. 15, 2011.

BOHMAN, James. The public spheres of the world citizen. In: BOHMAN, J.; LUTZ-BACHMANN, M. (Eds.). Perpetual peace: essays on Kant's cosmopolitan ideal. Cambridge: MIT Press, 1997.

CASTELLS, Manuel. The network society. In: HELD, David; McGREW, Anthony. The global transformation reader: an introduction to the globalization debate. Oxford: Polity Press, 2000.

CAVALLARO, James. Toward fair play: a decade of transformation and resistance in international human rights advocacy in Brazil. Chicago Journal of International Law, v. 3, n. 2, Fall, 2002.

COHEN, Jean. Globalization and sovereignty: rethinking legality, legitmacy and constitutionalism. Cambridge: Cambridge University Press, 2012. Janeiro, 2003.

Sociedade civil e globalização: repensando categorias. Revista Dados, v. 46, n. 3, Rio de

; ARATO, Andrew. Civil society and political theory. New Bakersville: MIT Press, 1999.

COSTA, Sérgio. Cosmopolitan democracy: conceptual deficits and political errors. Revista Brasileira de Ciências Sociais, v. 01, São Paulo, 2005.

. As cores de Ercília. Belo Horizonte: Editora UFMG, 2002.

DAHL, Robert. Can international organizations be democratic? A skeptic view. In: SHAPIRO, I.; HACKERCORDÓn, C. (Ed.). Democracy's Edges. Cambridge: Cambridge University Press, 1999. 
FALK, Richard. The world order between inter-state law and the law of humanity: the role of civil society. In: ARCHIBUGI; HELD (Eds.). Cosmopolitan democracy: an agenda for a new world order. Cambridge: Polity Press, 1995.

FRASER, Nancy. Scales of justice. New York: Columbia University Press, 2009.

. Rethinking the public sphere: a contribution to the critique of actually existing democracy. In:

CAlHOUN, C. (Org.). Habermas and the Public Sphere. Cambridge: MIT Press, 1996.

GÓMEZ, José Maria. Política e democracia em tempos de globalização. Petrópolis: Vozes, 2000.

HABERMAS, Jürgen. The constitutionalization of international law and the legitimation problems of a constitution for world society. Constellations, v. 15, n. 4, p. 443-455, 2008.

The divided west. Princeton: Princeton University Press. 2006.

. The inclusion of the other. Cambridge: MIT Press, 1999.

. Direito e democracia: entre faticidade e validade. Rio de Janeiro: Tempo Brasileiro, volume 2, 1997a.

. Kant's idea of perpetual peace, with the benefit of two hundred years' hindsight. In: BOHMAN, J.;

LUTZ-BACHMAnN, M. (Eds.). Perpetual peace. Cambridge: MIT Press, 1997.

Press, 1996.

Between facts and norms: contributions to a discourse theory of law and democracy. Cambridge: MIT

La constelación posnacional: ensayos políticos. Barcelona: Paidós, 2000.

HELD, David. Democracy and global order. Cambridge: Polity Press, 1995.

. International law. In: HELD, David; McGREW, Anthony. The global transformation reader: an

introduction to the globalization debate. Cambridge: Polity Press, 2000.

HURRELL, Andrew. Power, international institutions and the global south. Paper presented at the NYU Colloquium

Globalization and Its Discontents, on April 2000.

. Global inequality and international institutions. Metaphilosophy, v. 32, n. 1-2, Oxford, January 2001.

. The international dimensions of democratization in Latin America: the case of Brazil. In:

WHITEHEAD, L. (Ed.). The international dimensions of democratization: Europe and the Americas. Oxford: Oxford University Press, 2001.

winter 1995.

; WOODS, Ngaire. Globalization and inequality. Millenium: Journal of International Studies, v. 24, n. 3,

HERZ, Mônica Herz; HOFFMANN, Andréa. Organizações internacionais. Rio de Janeiro, Elsevier, 2004.

KANT, Immanuel. Perpetual peace: a Philosophical Sketch. Political writings. Translated by H. B. Nisbet.

Cambridge: Cambridge University Press, p. 94-130, 1991.

KECK, Margaret; SIKKINK, Kathryn. Activist beyond borders: advocacy networks in international politics. Ithaca:

Cornell University Press, 1998.

KINGSBURY, Benedict. Sovereignty and Inequality. European Journal of International Law 9, 1998.

KRASNER, Stephen. International Regimes. Ithaca: Cornell University Press, 1982.

LAFONT, Cristina. Global Governance and Human Rights (Spinoza Lectures Series, Amsterdam: van Gorcum, 2012.)

LUTZ-BACHMANN, Mathias. "Kant's Idea of Peace and a World Republic. In: BOHMAM, J.; LUTZ-

BACHMANN, M. (Eds.). Perpetual peace: essays on Kant's cosmopolitan ideal. Cambridge: MIT Press, 1997.

MAIA, Antonio. Espaço público e direitos humanos: considerações acerca da perspectiva habermasiana. Direito, estado e sociedade, Revista do Departamento de Direito da PUC-Rio, n. 11, 1997.

POWER, Michael. Habermas and the counterfactual imagination. In: ROSENFELD, Michael; ARATO, Andrew (Eds.). Habermas on Law and Democracy. Berkley and Los Angeles: University of California Press, 1998.

RISSE, Thomas; ROPP, Stephen C.; SIKKINK, Katryn (org.). The power of human rights: International norms and domestic change. Cambridge: Cambridge University Press, 1999.

. The Persistent Power of Human Rights. Cambridge: Cambridge University Press, 2013.

ROMANO, Cesare P. R. The proliferation of international judicial bodies: the pieces of the puzzle. Journal of International Law and Politics. v. 31, n. 4, p. 709-52, 1999.

SANDS, Philippe. Turtles or torturers: the transformation of international law. Journal of International Law and Politics, v. 33, NYU, p. 527, 2001.

SCHEUERMAN, William E. Postnational democracies without postnational states? Some skeptical reflections. Ethics \& Global Politics, v. 2, n. 1, p. 41-63, 2009.

SLAUGHTER, Anne-Marie. "International Law and International Relations Theory: a Dual Agenda" in American journal of international law, vol. 87, n. 205, 1993.

283, summer 2004

Sovereignty and power in a networked world order. Stanford Journal of International Law, v. 40, n.

A new world architecture: disaggregated states and government networks. Presented in the

Governance, Legitimacy and Democracy Workshop, in the NYU School of Law, on October 3 and 4, 2002. 
SIKKINK, Kathryn. Human rights, principled issues network and sovereignty in Latin America. International Organization, v. 47, n. 3, p .411-441, summer 1993.

. International human rights and sovereignty in Latin America. Conference Paper \#59. Presented at the Research Conference "Crossing national borders: invasion or involvement" held at Columbia University, December 61991.

THEREIN, Jean Phillipe; GOSSELIN, Guy. A democracia e os direitos humanos no hemisfério ocidental: um novo papel para a OEA. Contexto International, v. 19, n. 2, 1997.

TILLY, Charles. Social movements, 1768-2004. Boulder: Paradigm Publishers, 2004.

WEILER, Joseph. The geology of international law - governance, democracy and legitimacy, 2004. Disponível em: <http://www.zaoerv.de/64_2004/64_2004_3_a_547_562.pdf>. Acesso em: 12 fev. 2013.

. To be an european citizen: Eros and civilization. The Constitution of Europe. Cambridge, 2000.

WHITEHEAD, Lawrence. Three international dimensions of democracy. In: WHITEHEAD, L. (Ed.). The international dimensions of democratization: Europe and the Americas. Oxford: Oxford University Press, 2001.

\section{Márcia Nina Bernardes}

Rua Capitão Salomão, 30/106

Humaitá - 22271-040

Rio de Janeiro - RJ - Brasil

marcianblapuc-rio.br
Professora do Programa de Pós-Graduação EM DIREITO DA PUC-RIO

Coordenadora Acadêmica do Núcleo de Direitos Humanos do Departamento de DiReito da PUC-RIO

Doutora EM DiReito PELA NEW YoRK University (2007)

Mestre em Direito PELA NeW York University (2001)

Mestre em Direito Pela PUC-Rio (2000) HAUSER GLobal Scholar (NYU LAW'01) 